Voix et Images

voixetimages

\title{
Réjean Ducharme : du mythe au roman
}

\section{Nicole Bourbonnais}

Volume 18, numéro 3 (54), printemps 1993

Littérature, folie, altérité

URI : https://id.erudit.org/iderudit/201053ar

DOI : https://doi.org/10.7202/201053ar

Aller au sommaire du numéro

\section{Éditeur(s)}

Université du Québec à Montréal

\section{ISSN}

0318-9201 (imprimé)

1705-933X (numérique)

Découvrir la revue

\section{Citer cet article}

Bourbonnais, N. (1993). Réjean Ducharme : du mythe au roman. Voix et Images, 18(3), 593-597. https://doi.org/10.7202/201053ar d'utilisation que vous pouvez consulter en ligne.

https://apropos.erudit.org/fr/usagers/politique-dutilisation/ 


\section{Réjean Ducharme: du mythe au roman}

Nicole Bourbonnais, Université d'Ottawa

Ducharme "l'inquiétant ${ }^{1}$ " serait-il en passe de devenir clair, limpide; rassurant? Pourtant, les lecteurs de Réjean Ducharme savent bien que ses romans ne se laissent pas aisément réduire à une simple équation. Polysémiques, ludiques, métäphoriques, truffés de références littéraires, ils excitent spontanément la curiosité et appellent le déchiffrement. Mais, jusqu'ici, si plusieurs critiques se sont lancés dans l'herméneutique ducharmienne, ils s'en sont tenus, à une exception près $^{2}$, à des articles de fond portant sur des aspects circonscrits, la plupart du temps reliés au travail de l'écriture.

Il fallait donc que ce fut fait. Qu'une exégèse détaillée des belles œuvres obscures vienne éclairer la lanterne du lecteur. C'est à la fondatrice et directrice du Centre d'études québécoises de Bologne, Franca Marcato-Falzoni, que nous devons le premier ouvrage de synthèse sur la trilogie de Réjean Ducharme, ouvrage intitulé Du mythe au roman, une triologie ducharmienne ${ }^{3}$. En ces temps où il est de plus en plus question d'altérité et de différence, l'étude d'une œuvre québécoise en provenance d'Italie apporte un témoignage éloquent 
de ce que peut offrir l'ouverture vers l'Autre. Mentionnons à cet égard que le livre est doté d'une excellente préface de Naïm Kattan, natif de Bagdad, Québécois d'adoption et auteur d'œuvres où la conscience de l'altérité s'exprime avec finesse et justesse.

Certes, tout n'est pas inédit dans Du mythe au roman. Plus d'un critique a déjà noté les thèmes de la quête de l'idéal et de l'inévitable soumission à la réalité. De son côté, Gilles Marcotte le premier avait remarqué que chez Ducharme le roman s'associe à la ville et au sexe ou encore avait repéré la "méfiance fondamentale" de Mille Milles ( $L e$ Nez qui voque) à l'égard "de tout ce qui porte le nom d'histoire ${ }^{4}$ (y compris l'Histoire). Mais il n'en reste pas moins que l'ouvrage de Marcato-Falzoni possède d'indéniables qualités heuristiques et qu'elle éclaire plus d'une facette obscure de l'œuvre.

En premier lieu, l'auteure de l'essai a le grand mérite d'établir clairement le fil conducteur de la trilogie et de mettre en lumière les liens aussi bien formels que sémantiques qui unissent les trois romans. Ainsi, L'Océantume, premier roman dans l'ordre de composition ${ }^{5}$, retient le mythe comme point de départ, L'Avalée des avalés, le deuxième, prend appui sur la religion, forme dégradée du mythe, tandis que le troisième, Le Nez qui voque, adopte l'Histoire à la fois comme source et comme repoussoir:

Respectivement centrés sur le mythe, la religion et l'histoire, ces trois romans figurent en fait le chemin de l'humanité qui, partie de cet âge que le mythe nomme d'or, a traversé l'époque de la foi dans l'idéal pour aboutir à l'histoire, chaîne d'événements immanents qui ne laissent place à aucune illusion (p. 12).

En effet, chacun de ces romans, d'expliquer Franca Marcato-Falzoni, se tourne vers le passé, vers un "modèle exemplaire" (p. 18) qu'il tente ou de supplanter ou de s'approprier pour créer un présent idéal et merveilleux. Mais, chaque fois, cette traversée du temps se solde par un échec: le protagoniste-narrateur se butte à la réalité sordide mais toute-puissante et se voit obligé de se détourner du conte qu'il avait rêvé d'écrire pour basculer dans le roman, genre qui s'immerge dans le réel et le sexe. Le projet de restauration d'un âge d'or ne s'imagine donc pas sans le projet d'écriture. L'essayiste met aussi en lumière la structure ternaire de chaque roman - reproduite dans le macrocosme qu'est la trilogie - qui emprunte le parcours qui va de la naissance d'un idéal (l'enfance) à la tentative de le réaliser (lors de l'adolescence) pour aboutir à l'échec (à l'âge adulte).

Pour chacun des romans, Marcato-Falzoni suit pas à pas les étapes de la transformation de la quête du protagoniste et fournit une analyse 
convaincante' de sa thèse alors qu'elle reconstruit sous nos yeux, minutieusement, l'édifice savant et ingénieux de l'œuvre où un enfant grandit et se corrompt au même rythme que l'humanité ou que le pays qui l'a vu naître. Ainsi, dans L'Océantume, la quête d'Iode estelle vue comme une entreprise de renouvellement culturel du pays à partir de la tentative de réintégration du Mythe dans nos vies comme du conte dans l'écriture. De dégradation en dégradation, du mythe au conte de fées, on en arrive au roman, à la "dernière entreprise cognitive. (p. 87), soit à l'exploration du réel.

En cours de route, la critique lève le voile sur quelques mystères qui entourent noms et personnages. Nous apprenons de la sorte qu'Ino-Inachos, apathique, aboulique, est symbolique de l'imaginaire collectif défaillant, qui “autrefois alimenté par les gestes mythiques des Héros [...] reste enraciné dans le lointain passé, dans les origines d'un pays où plus rien n'existe" (p. 44-45). Sa tentative de renaissance par un rigoureux entraînement sportif qui se veut un exercice spirituel ne fera de lui qu'un "animal de compétition" (p. 86). Nous apprenons aussi que Michel Lange, alias Michel-Ange, représente "l'un des mythes actuels les plus fascinants" (p. 59), soit le mythe cinématographique moderne, avatar dégradé du Mythe des dieux.

Dans chacune de ses trois analyses, Franca Marcato-Falzoni désigne les étapes- de l'itinéraire de mutation par des sous-titres qui constituent autant de jalons de la quête. Ainsi, dans L'Avalée des avalés, qui s'inscrit tout entier sous le signe de la religion, l'auteure pose d'abord les fondements de la Sainte Famille, où la rebelle Bérénice se familiarise avec les abus de pouvoir de deux grandes religions monothéistes. Révoltée, la narratrice entreprend de recréer le Paradis sur terre, mais sans Dieu. Dans une parodie de la Genèse, elle s'emploie à composer un récit profane qui inverse les signes des saintes Écritures. La Mère-Église deviendra Chamomor tandis que les chats, ses associés, meurent et se succèdent comme autant de Papes: Mauriac I, II et III: *Reproduction profane et profanatrice, où le rôle de Yahveh est tenu par Christian et Bérénice, premier couple fraternel homme-dieu du paradis sur terre. (p. 123).

Mais, impuissante à substituer à la transcendance divine son propre intellect, Bérénice se mue en Ange rebelle. À New York, elle entre de plein fouet dans la réalité de la Loi de Yahveh qui régit le monde matérialiste et pornographique, celui que traduit le roman. Le retour en arrière désormais impossible, Bérénice se tourne du côté de la Terre promise, vers Israël, symbole de la liberté du peuple hébraïque. Mais dans ce pays qui n'a que la guerre comme religion, la liberté, réduite à l'ordre matériel, s'identifie au fanatisme. 
Avec Le Nez qui voque, Franca Marcato-Falzoni s'attaque comme d'autres avant elle à l'énigmatique équivoque du titre proposant une clef fort astucieuse:

$\mathrm{N}=$ Mille Milles $=\mathrm{Un}$ nez qui voque $=$ Un $\mathrm{N}$ qui évoque - Le nez qui voque = le $N$ (narrateur) qui évoque (p. 188).

Ainsi, l'évocation-invocation serait le processus qui fonde l'entreprise narrative de Mille Milles axée sur l'allusif et le "système indirect [...] qui suppose un champ magique et imaginaire" (p. 192). L'auteure met donc l'accent sur le caractère métaphorique de l'écriture de ce troisième roman qui dès l'incipit se réclame de la poésie avec Nelligan et de la folie avec l'allusion à l'Éloge de la folie d'Érasme. Mille Milles, l'écrivain-enfant, se soumet "au pouvoir magique des invocations" afin d'oublier l'Histoire réelle qui est celle de la défaite et de la soumission des Canadiens français pour écrire un conte où le Nouveau-Québec serait le lieu utopique par excellence avec la fabuleuse et pure Chateaugué comme héroöne. Quant à Questa (en italien, cette choselà, le cela par opposition au ça), femme-objet, mère nourricière, elle sustente l'écrivain d'aliments du réel et va jusqu'à lui imposer son "genres, soit le genre romanesque. Vaincu, Mille Milles abandonne ses rêves et son cahier pour le journal-roman, pour la transcription du quotidien. Ainsi, Le Nez qui voque serait avant tout une "métaphore de l'oubli qui, en dépit de toute tentative de remémoration, recouvre le passé " (p. 243).

$\mathrm{Au}$ terme de cette lecture éclairante, on regrettera seulement l'absence de conclusion, étonnante après trois chapitres d'analyse détaillée et de cheminement attentif. L'étude apparaît alors comme laissée en plan, comme en suspens. Une conclusion aurait permis d'effectuer une sortie hors de la diégèse, hors de cette chute récurrente dans la réalité pour constater qu'en définitive, ce qui demeure, c'est le puissant imaginaire des œuvres ducharmiennes qui fait vivre tout ensemble passé, présent et avenir.

1. Cf. Michel van Schendel, «Ducharme l'inquiétant, Littérature canadiennefrançaise, Conférences J.-A. Sève, Montréal, Presses de l'Université de Montréal, 1969, p. 216-234.

2. Renée Leduc-Park, Réjean Ducharme, Nietzsche et Dionysos, Québec, Presses de l'Université Laval, 1982.

3. Franca Marcato-Falzoni, Du mythe au roman, une trilogie ducharmienne, traduit de l'italien par Javier Garcia Méndez, Montréal, VLB éditeur, 1992, 264 p. On lui doit aussi la publication du livre suivant: La deriva delle francofonie, atti dei seminari annuali di Letterature Francofone, * Autour de l'univers souterrain dans la littérature québécoise., Bologne, Cooperativa Libraria Universitaria Editrice Bologna, 1990, 265 p. 
4. Gilles Marcotte, Littérature et Circonstances, Montréal, l'Hexagone, 1989, p. 180-181.

5. Les trois romans ont été publiés chez Gallimard aux dates suivantes: L'Avalée des avalés, 1966, Le Nez qui voque, 1967 et L'Océantume, 1968. Toutefois, l'ordre de composition est celui qui est indiqué dans le compte rendu: une note de l'auteure (p. 13) précise que Réjean Ducharme lui-même a confirmé l'ordre de composition des romans. 